\title{
EDITORIAL
}

\section{BIDIRECTIONAL COMMUNICATION BETWEEN BRAIN AND MUSCLE}

\author{
J.E. MORLEY

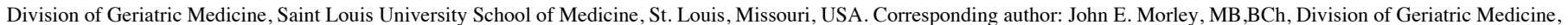 \\ Saint Louis University School of Medicine, 1402 S. Grand Blvd., M238, St. Louis, MO 63104, Email: john.morley@health.slu.edu
}

Key words: Brain communication, muscle, function.

"What we have here is a failure to communicate."

Cool Hand Luke

Communication between the brain and muscle plays a key role in maintaining the function of an individual. A classical example of this failure to communicate is after a stroke which leads to a failure of the brain to communicate with the periphery resulting in the muscle becoming flaccid. With aging there is a gradual decline in the communication between the central nervous system and skeletal muscle. This leads to a decrease in speed of movement, weakness, an increased tendency to fall and eventually a decline in function.

A number of studies have shown that deterioration in brain function leads to a decline in grip strength and walking speed. For example, older persons with the lowest MiniMental Status Examination score and poor verbal ability had lower grip strength (1). Ten percent variance in gait speed is due to the amyloid-beta burden in the brain together with the presence of the apolipoprotein E4 gene (2). A classical example of the brain-muscle communication decrease with aging is the decline in the ability of old persons with dementia or Parkinson's disease to "dual task" (3). "Dual tasking" deficit is the inability to maintain walking speed while being asked to carry out a mental task. Both children up to 12 and older persons have a decrease in walking speed when asked to do an arithmetic problem.

With aging there is a decrease in axonal communication leading to a decline in the connection between the cortex and the spinal cord (4). The decline in dopamine receptors with aging results in slowed reaction times (5). With aging there is a decrease in motor unit numbers leading to fiber size heterogeneity and fiber grouping similar to the changes seen in amyotrophic lateral sclerosis and a loss of type 2 muscle fibers (6). When this is pronounced, it results in sarcopenia. In addition, the increase in adenosine (A1) inhibitory receptors over the adenosine $2 \mathrm{~A}$ receptors results in decreased muscle force (7).

\section{From Muscle to Brain}

"Methinks that the moment my legs begin to move, My thoughts begin to flow" $\sim$ Henry David Thoreau, 1851

Physical exercise increases hippocampal volume in older persons (8). In persons with mild cognitive impairment there is an increase in brain activation after 12 weeks of training (9). Exercise increases mental performance and function in older persons (10-13). Overall, exercise increases neurogenesis, neuronal maturation, angiogenesis, hippocampal volume and learning and memory in mice (14). Exercise directly increases BDNF, APP and BACE-1 in Alzheimer's disease rat brain (15).

For muscle to produce these effects it produces a variety of myokines that have a direct effect on the brain (16). Among these myokines the ones that have been shown to have effects on the central nervous system include insulin-growth factor-1, brain derived nerve growth factor, cathepsin-B, fibroblast growth factor-1 and irisin (17). Irisin has been considered a major peptide communicator (18), but recently studies have suggested that the assays that have been used are very nonspecific $(19,20)$.

Another effect of muscle on the brain is to increase fatigue (21). Exercising muscle increases tryptophan and branched chain amino acids release in the blood leading to an increase in tryptophan in the brain $(22,23)$. In the brain tryptophan is converted into serotonin that inhibits neuronal activity leading to a sense of fatigue (24). Exercise also reverses depressive behaviors (25).

\section{Cognitive Frailty}

Cognitive frailty is defined as a person with reduced cognitive reserve associated with physical frailty $(26,27)$ (Figure 1). Persons with cognitive frailty have worse physical outcomes than persons who only have frailty (28-30).

Persons who have an increase in regional white matter burden (vascular disease) have increased balance and gait disorders, falls, urge incontinence, functional decline, and disability and worse executive function (31-33). Besides the 


\section{THE JOURNAL OF NUTRITION, HEALTH \& AGING@}

role of vascular disease producing cognitive frailty, another causative factor is inflammatory cytokines. Inflammatory cytokines are elevated in physical frailty (34). The cytokines can cross the blood brain barrier leading to impaired cognition (35).

\section{Figure 1}

Pathophysiology of Cognitive Frailty and Its Outcomes

\begin{tabular}{|l|l|l|}
\hline Causes & & Negative Outcomes \\
\hline $\begin{array}{l}\text { Aging } \\
\text { Genetics } \\
\text { Inflammation } \\
\text { Vascular Disease } \\
\text { Diabetes Mellitus } \\
\text { Socioeconomic factors } \\
\text { Other diseases } \\
\text { Lack of exercise }\end{array}$ & Physical Frailty & \begin{tabular}{l} 
Falls \\
Depression \\
Slow gait \\
Dual tasking deficit \\
\cline { 2 - 3 } \\
\cline { 2 - 3 } \\
Functional decline \\
Hospitalizations \\
Nursing home \\
Mortality
\end{tabular} \\
\hline
\end{tabular}

Motoric Cognitive Risk Syndrome is similar to cognitive frailty (36). It is defined as an older person with slow gait and memory complaints, without dementia. Its pathophysiology is considered to be due to decreased gray matter volume and hippocampal volume together with an increase in white matter hyperintensities.

\section{Conclusion}

A failure to communicate between brain-muscle-brain plays a significant role in the aging process. This failure leads to frailty, sarcopenia, fatigue, depression and cognitive frailty (Figure 2).

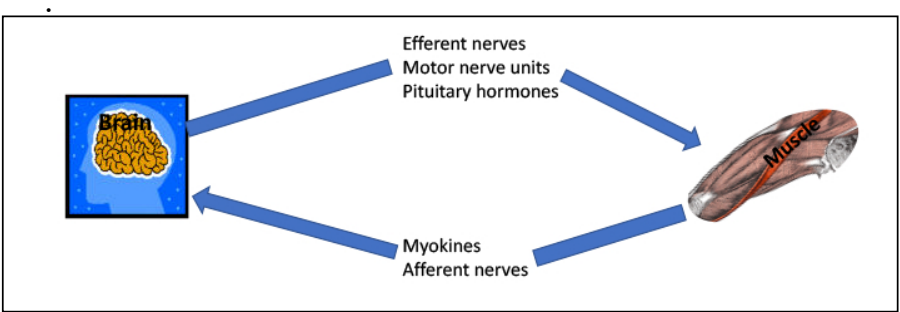

Disclosures: The authors declare there are no conflicts

\section{References}

1. Carson RG. Get a grip: Individual variations in grip strength are a marker of brain health. Neurobiol Aging 2018;71:189-222.

2. Del Campo N, Payoux P, Djilali A, et al; MPT/DSA Study Group. Relationship of regional brain $\beta$-amyloid to gait speed. Neurology 2016;86:36-43.

3. Chu YH, Tang PF, Peng YC, Chen HY. Meta-analysis of type and complexity of a secondary task during walking on the prediction of elderly falls. Geriatr Gerontol Int 2013;13:289-297.

4. Manini TM, Hong SL, Clark BC. Aging and muscle: A neuron's perspective. Curr Opin Clin Nutr Metab Care 2013 January; 16(1). Doi:10.1097/ MCO.0b013e32835b5880.

5. MacDonald SW, Karlsson S, Rieckmann A, et al. Aging-related increases in behavioral variability: Relations to losses of dopamine D1 receptors. J Neurosci 2012;32:8186-8191.

6. Drey M, Grosch C, Neuwirth C, et al. The motor unit number index (MUNIX) in sarcopenic patients. Exp Gerontol 2013;48:381-384.

7. Kandel ER, Schwartz JH, Fessell TM, et al. Principles of Neural Science. 5. McGraw-Hill Companies, Inc; 2012.
8. Firth J, Stubbs B, Vancampfort D, et al. Effect of aerobic exercise on hippocampal volume in humans: A systematic review and meta-analysis. Neuroimage 2018;166:230-238.

9. Smith JC, Nielson KA, Antuono P, et al. Semantic memory functional MRI and cognitive function after exercise intervention in mild cognitive impairment. J Alzheimers Dis 2013;37:197-215.

10. Loprinzi PD, Blough J, Ryu S, Kang M. Experimental effects of exercise on memory function among mild cognitive impairment: Systematic review and meta-analysis. Phys Sportsmed 2018;Sep 22. Doi:10.1080/00913847.2018.1527647 [Epub ahead of print]

11. Du Z, Li Y, Li J, et al. Physical activity can improve cognition in patients with Alzheimer's disease: a systematic review and meta-analysis of randomized controlled trials. Clin Interv Aging 2018;13:1593-1603.

12. Auyeung TW, Lee JS, Kwok T, Woo J. Physical frailty predicts future cognitive decline - a four-year prospective study in 2737 cognitively normal older adults. J Nutr Health Aging 2011;15:690-694.

13. Miyawaki CE, Bouldin ED, Kumar GS, McGuire LC. Associations between physical activity and cognitive functioning among middle-aged and older adults. J Nutr Health Aging 2017;21:637-647.

14. Guerrieri D, oon HY, van Praag H. Exercise in a pill: The latest on exercise-mimetics. Brain Plasticity 2 (2016/2017) 153-169.

15. Alkadhi KA. Exercise as a positive modulator of brain function. Mol Neurobiol 2018;55:3112-3130.

16. Delezie J, Handschin C. Endocrine crosstalk between skeletal muscle and the brain Front Neurol 2018 Aug 24 doi.org/10.3389/fneur.2018.00798.

17. Son JS, Chae SA, Testroet ED, et al. Exercise-induced myokines: A brief review of controversial issues of this decade. Expert Rev Endocrinol Metab 2018;13:51-58

18. Grygiel-Gorniak B, Puszczewicz M. A review on irisin, a new protagonist that mediates muscle-adipose-bone-neuron connectivity. Eur Rev Med Pharmacol Sci 2017;21:4687-4693.

19. Kaluzna M, Hoppe K, Schwermer K, et al. Preanalytical, analytical, and postanalytical errors in the measurement of irisin levels. Authors' reply. Pol Arch Intern Med 2017;127(9):643-644.

20. Hecksteden A, Wegmann M, Steffen A, et al. Irisin and exercise training in humans - results from a randomized controlled training trial. BMC Med 2013 Nov 5;11:235. Doi:10.1186/1741-715-11-235.

21. Taylor JL, Amann M, Duchateau J, et al. Neural contributions to muscle fatigue: From the brain to the muscle and back again. Med Sci Sports Exerc 2016 Nov;48(11):2294-2306.

22. Cervenka I, Agudelo LZ, Ruas JL. Kynurenines: Tryptophan's metabolites in exercise, inflammation, and mental health. Science 2017 Jul 28;357(6349). Doi:10.1126/science.aaf9794

23. Shortz AE, Pickens A, Zheng Q, Mehta RK. The effect of cognitive fatigue on prefrontal cortex correlates of neuromuscular fatigue in older women. J NeuroEngineering and Rehab 2015;12:115. Doi:10.1186/s12984-015-0108-3

24. Cordeiro LMS, Rabelo PCR, Moraes MM, et al. Physical exercise-induce fatigue: The role of serotonergic and dopaminergic systems. Braz J Med Biol Res 2017;50:e6432. Doi: 10.1590/1414-431X2017643

25. Schuch FB, Vancampfort D, Firth J, et al. Physical activity and incident depression: A meta-analysis of prospective cohort studies. A, J Psychiatry 2018;175:631-648.

26. Malmstrom TK, Morley JE. Frailty and cognition: Linking two common syndromes in older persons. J Nutr Health Aging 2013;17:723-725.

27. Kelaiditi E, Cesari M, Canevelli M, et al. Cognitive frailty: Rational and definition from an I.A.N.A./I.A.G.G.) international consensus group. J Nutr Health Aging 2013;17:726-734.

28. Yu R, Morley JE, Kwok T, et al. The effects of combinations of cognitive impairment and pre-frailty on adverse outcomes from a prospective community-based cohor study of older Chinese people. Front Med (Lausanne) 2018 Mar 6;5:50. DOI: 10.3389/fmed.2018.00050. eCollection

29. Morley JE, Morris JC, Berg-Weger M, et al. Brain health: The importance of recognizing cognitive impairment: An IAGG consensus conference. J Am Med Dir Assoc 2015; 16:731-739.

30. Canevelli M, Cesari M. Cognitive frailty: What is still missing? J Nutr Health Aging 2015;19:273-275.

31. Morley JE. White matter lesions (leukoaraiosis): A major cause of falls. J Am Med Dir Assoc 2015;16:441-443.

32. Pantoni L, Fierini F, Poggesi A; LADIS Study Group. Impact of cerebral white matte changes on functionality in older adults: An overview of the LADIS study results and future directions. Geriatr Gerontol Int 2015;15(Suppl 10:10-16.

33. Pantoni L, Poggesi A, Inzitari D. The relation between white-matter lesions and cognition. Curr Opin Neurol 2007 Aug;20(4):390-397.

34. Chode S, Malmstrom TK, Miller DK, Morley JE. Frailty, diabetes, and mortality in middle-aged African Americans. J Nutr Health Aging 2016;20:854-859.

35. Banks WA, Farr SA, Morley JE. Entry of blood-borne cytokines into the central nervous system: Effects on cognitive processes. Neuroimmunomodulation 2002 2003;10:319-327.

36. Allali G, Ayers EI, Verghese J. Motoric cognitive risk syndrome subtypes and cognitive profiles. J Gerontol A Biol Sci Med Sci 2016;71:378-384 